\title{
CLAVE DE IDENTIFICACIÓN PARA AMMONITES DEL GÉNERO BERRIASELLA DE LA FORMACIÓN PUENTE PIEDRA, MIEMBRO PUENTE INGA, LIMA.
}

Vera Alleman $\mathrm{H}$. Facultad de Ciencias biológicas, Universidad Ricardo Palma.

\section{RESUMEN}

Se presenta una clave de identificación basada sobre las características morfológicas distintivas de las impresiones de los moldes internos de las 26 especies de Berriasella registradas en la unidad litoestratigráfica.

Palabras Claves : Berriasella, clave de identificación, Lima.

\section{SUMMARY}

A key for identification of the 26 species of Berriasella from the litostratigraphic unit is presented based up the distintif morfologic caracteristics of inner impressions.

Key Words : Berriasella, identification key, Lima.

\section{INTRODUCCION}

Los ammonites están repartidos sobre la totalidad del espesor de los afloramientos de la Formación. El género Berriasella se destaca por el gran número y la variedad de especies, diferentes entre sí por el número y la curva de las costillas ornamentales. Pero todas las especies tienen en común, lo que las distinguen de los demás géneros de ammonites del lugar : un ombligo amplio, una involución pequeña de las vueltas y las costillas bien definidas, de las cuales la mayoría se bifurcan a partir de la mitad de la altura del flanco.

La fauna es endémica y ha sido estudiada por Carlos Lisson y Rosalvina Rivera. Pedro Tapia hizo una revisión bibliográfica detallada cuyo resultado fue que de las 26 especies descritas y citadas en la literatura varias pueden ser consideradas sinónimas y solo siguen válidas a penas un número de 10 especies.

\section{MATERIAL Y MÉTODOS}

Los fósiles consisten en moldes internos dejados en una lutita de grano fino por la disolución post - fosilización de las partes conchíferas de los animales. No se conoce la línea sutural. La metodología aplicada a la determinación sistemática consiste en la elaboración de una clave dicotómica de aplicación localizada.

\section{RESULTADOS}

\section{PARTE SISTEMÁTICA}

Phyllum Mollusca * (según Moore 1957)

Clase Cephalopoda Leach, 1817

Orden Ammonoidea Zittel, 1884

Suborden Ammonitina Hyatt, 1889

Superfamilia Perisphinctaceae

Steinmann, 1890

Familia Berriasellidae Spath, 1922

Subfamilia Berriasellinae Spath, 1922

Género Berriasella Uhlig, 1905

\section{CLAVE DE IDENTIFICACIÓN}

1. Pared umbilical con hombro bien definido 2

Pared umbilical con hombro no bien definido

2. Costillas flexuosas

Costillas relativamente rectas y radiales 4

3. Costillas fuertes y afiladas que se interrumpen formando un nudo al llegar a la línea sutural :

Berriasella limensis (Lisson, 1907). 
Costillas fuertes que se dividen en dos ramas de igual grosor que atraviesan el borde externo sin interrumpirse:

Berriasella chillonensis Rivera, 1951.

4. Costillas relativamente rectas fuertes 5 Costillas relativamente rectas finas 6

5. Costillas relativamente rectas fuertes separadas por interespacios mayores y terminándose en bultos en el borde externo :

Berriasella laxicosta (Steuer, 1897).

6. Costillas relativamente rectas finas de sección cuadrángular separadas por interespacios planos y más anchos que las costillas :

Berriasella aff. B. tenuicostata Burck.

Costillas relativamente rectás finas diferenciadas con variación y bifuración visible de la vuelta anterior :

Berriasella candelaensis Rivera, 1951.

7. Borde umbilical indefinido 8 Borde umbilical poco definido

8. Con costillas intercaladas :

Berriasella callistoides (Behrendsen, 1891).

Sin costillas intercaladas :

Berriasella peruviana Rivera, 1951.

9. Costillas que se dividen en dos ramas de igual grosor

Costillas que no se dividen en dos ramas de igual grosor.

10. Costillas fuertes que se interrumpen al borde externo :

Berriasella calisto (d' Orbigny, 1847).

Costillas que no forman nudo y algunos se trifurcan:

Berriasella curvicostata Rivera, 1951.
11. Costillas con engrosamiento en el borde umbilical :

Berriasella broggii Rivera, 1951.

\section{DISCUSIÓN}

De las 24 especies de ammonites determinados o actualizados como Berriasella es recomendable de elaborar la siguiente sinonimía en referencia de las investigaciones bibliográficas realizadas por Pedro Tapia (1988).

Ammonites Calisto d' Orbigny, $1847=$ Berriasella callisto (d' Orbigny, 1847).

Berriasella Callisto d' Orbigny = Berriasella callisto (d' Orbigny, 1847).

Berriasella cf callistoides Behrendsen = Beriasella callistoides (Beherendsen, 1891)

Berriasella limensis Lisson $=$ Berriasella limensis (Lisson, 1907).

Beriasella tenuicostata Burckhardt, $1912=$ Berriasella aff B. tenuicostata Buckhardt, 1912.

Berriasella (Paradontoceras) calistoides Behrendsen $=$ Berriasella callistoides (Behrendsen, 1891).

Cosmoceras limense Lisson, $1907=$ Berriasella limensis (Lisson, 1907).

Hoplites (Berriasella) callisto d' Orbigny = Berriasella callisto ('d' Orbigny, 1847).

Hoplites (Berriasella) cf callistoides Behrendsen $=$ Berriasella callistoides (Behrendsen, 1891).

Hoplites callistoides Behrendsen, $1891=$ Berriasella callistoides ( Behrendsen, 1891).

Hoplites heteroptychus Pavlow var peruana Lisson, $1907=$ Berriasella limensis (Lisson, 1907).

Hoplites (Neocomites) limensis ( Lisson) $=$ Berriasella limensis (Lisson, 1907). 
Neocomites limensis Lisson $=$ Berriasella limensis (Lisson, 1907).

Odontoceras callistoides Behrendsen emend Steuer $=$ Berriasella callistoides (Behrendsen, 1891).

Parodontoceras callistoides Behrendsen $=$ Berriasella callistoides ( Behrendsen, 1891).

\section{REFERENCIAS BIBLIOGRÁFICAS}

1. Lisson, C. 1907. Contribución a la Geología de Lima y sus Alrededores. Gil, Lima, 125 pp.

2. Rivera, R. 1951. La Fauna de los Estratos Puente Inga, Lima. Bol. Soc. geol. Perú. 22: 1-53.
3. Moore, R. 1957. Treatise on Invertebrate Paleontology.Part $\mathrm{L}$, Mollusca V.4.De. Univ. Of Kansas.

4. Rivera, R y Alleman V. 1974. Fósiles "tipos"conservados en el Perú. Bol. Soc. Geol. Perú. 44: 80-105

5. Tapia, P. 1988. Revisión bibliográfica de los Ammonoidea (Cephalopoda, Mollusca) del Cretáceo de Lima. Tesis Bach. en Biología URP. Lima.

\section{AGRADECIMIENTOS}

El presente estudio se ha realizado con el apoyo de la Facultad de Ciencias biológicas de la Universidad Ricardo Palma, por lo cual le estamos reconocidos. 